\title{
Trees as Bioindicators of Environmental Pollution and Its Impact on Wood Chemical Composition
}

\author{
Carmen-Alice Teacă \\ Trees provide one of the most versatile biomass resources for many \\ applications, namely wood. The chemical composition of wood determines \\ its properties, being of real significance for its further capitalization, and \\ depending on many factors. In nature, trees' biomass is subjected to \\ considerable pollution stress with further alteration of their normal growth \\ conditions. Some correlations have been established between wood's \\ chemical composition and its further exploitation accordingly to particular \\ circumstances of climate changes and pollution. The content of the main \\ structural polymers from wood, cellulose and lignin, as well other \\ components undergoes notable changes under the influence of pollution \\ phenomena.
}

Keywords: Trees; Bioindication; Pollution; Wood; Chemical Composition

Contact information: "Petru Poni" Institute of Macromolecular Chemistry, Centre of Advanced Research in Bionanoconjugates and Biopolymers, 41A Grigore Ghica-Voda Alley, Iasi, Romania;

e-mail: cateaca@icmpp.ro; cateacal4@yahoo.com

\section{Trees and Their Sensitivity towards Environmental Pollution}

Trees, a wonder of nature that unceasingly amazes us, are living systems that provide one of the most widely used biomass resources employed in many applications, namely wood. When we try to understand wood, we observe how nature, again, designed a beautiful and complex structure using polymers - cellulose, lignin, hemicelluloses - and other compounds - extractives - which impart varied properties (Lemonick 2018).

The main wood components are also the most versatile natural polymers used in a wide range of applications, and are as follows:

- cellulose, a polysaccharide consisting of $\beta(1-4)$ linked D-glucose units, which is responsible for wood's tensile strength and represents about half of the total amount of wood polymers,

- lignin, an aromatic polymer based on cross-linked phenolic units, which is responsible for wood's compressive strength.

Traditionally, forest trees' biomass is the main raw material for pulp and paper production (Lemonick 2018). It has a pre-designed chemical composition through biosynthesis processes from nature. Nowadays, the modern biorefinery approaches place certain demands on the raw material to produce end-products with desired features. In this context of the existent interrelation between chemical reactions involved in refining biomass and the raw material structural properties, it is of real significance to consider the variability in the chemical composition of trees biomass. This differs to a large extent as proportions of cellulose, lignin, hemicelluloses, and extractive compounds in different tree species (e.g. softwood, hardwood), as well as in trees parts (e.g. trunk, bark, branches, needles-in case of coniferous species, leaves, stumps which include bark, roots). 
In nature, forest trees' biomass is subjected to significant and varied pollution stress, which affects their vital lifetime physiological processes. A significant degradation of the forest ecosystem is noticed, mainly in the advanced countries, in close relation with large emission loadings; this phenomenon being primarily connected to root system development (Albrechtová et al. 2016). Deforestation and trees damage can be assuredly attributed to the air pollution that inflicts the primary degradation, which is subsequently aggravated by opportunistic attacks (biologic, seasonal temperature cycles or occasionally occurring events, UV exposure, ozone, etc.). In effect, the metabolic processes in trees are severely affected, and this behavior is manifested by the various nutrients' deficiencies, mainly minerals. Experimental data obtained through different investigation techniques (chemical composition analysis of raw wood and wood ash specimens, FTIR and X-ray spectroscopies, and dendrochronology) evidenced all these changes in trees physiology, indicating their high capacity to retain some pollutants and assimilate them in metabolism cycles, even at the cost of vitality and losing nutrients. This behavior may be an adaptive feature of trees, illustrating their capacity to use non-specific nutrient sources, hence their ability to adapt their metabolism to the environmental conditions. Thus, trees may become the most reliable bioindicators of the health/pollution of their growth environment.

This is the reason why trees should be considered as dynamic, living systems with a high complexity given by the many elements and different functional components that interrelate and interact in a specific manner. This is more obvious when it comes to the harmful effects of pollution, manifested as the decline of the foliage and/or roots, and their impact on the vital processes in trees as a whole. Even more, the impact of accidental pollution cases is stronger, while a clean environment maintained for short terms has a minimal effect (Leonelli et al. 2012; Kocić et al. 2014).

In Figure 1, a schematic representation of some possible interactions of relevance to forest dieback in relation with climate alterations and air pollution is given.

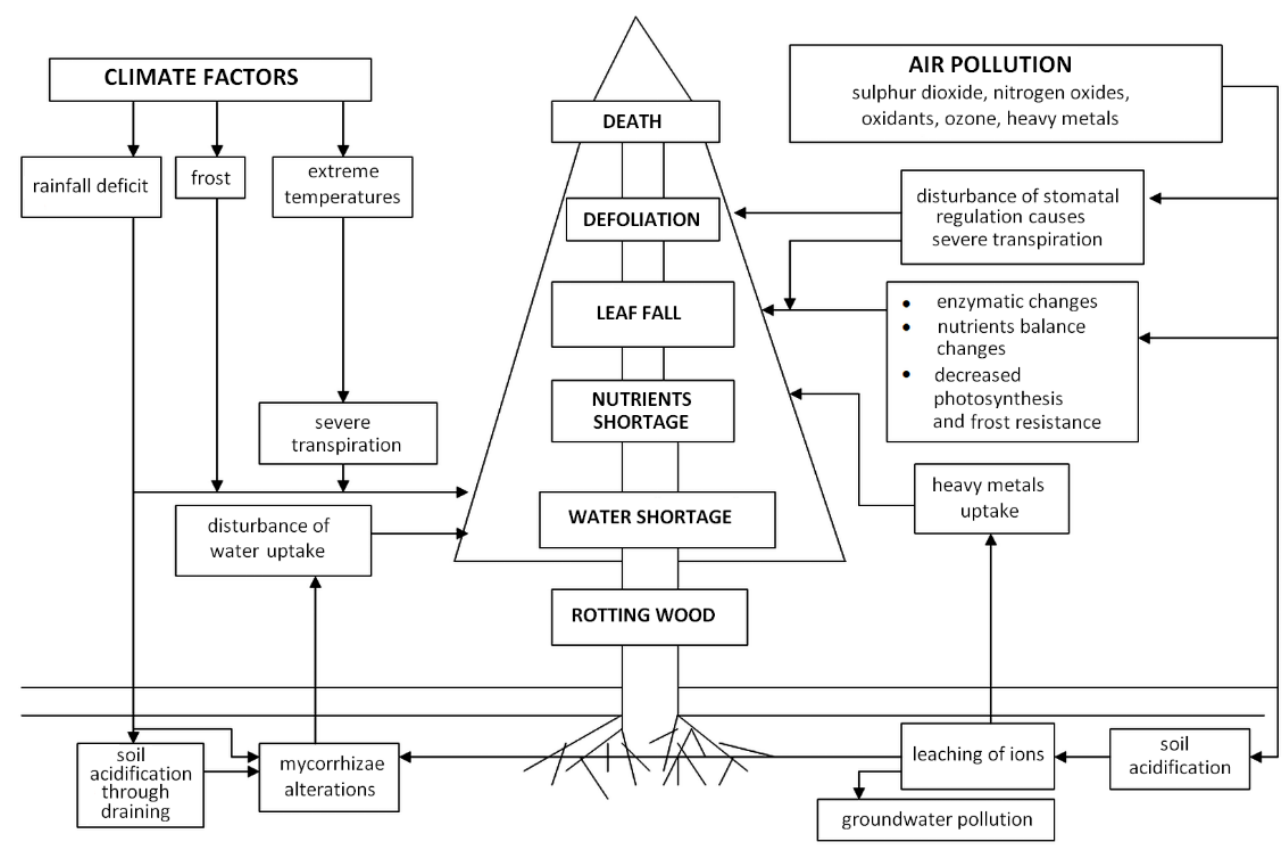

Fig. 1. Some possible interactions relevant to the forest dieback in relation with climate changes and air pollution (adapted and re-drawn from the data of Schäfer et al. 1988) 


\section{Impact on Wood Chemical Composition}

The chemical composition of wood determines its properties and is of great importance for further chemical-technological utilization. For example, the pulp and paper industry requires wood with high cellulose/lignin ratio. Likewise, wood material quality is important for the manufacture of fiberboards, where the wood filler significantly improves the physical properties of boards, mainly the mechanical ones. When energy production purposes are envisaged, the wood species with high lignin content is preferable, considering the positive effect of lignin on the resulting calorific value. In this case, it is also important to consider the composition of wood ash (the residue formed after the combustion of wood and wood products - chips, sawdust, bark, unbleached wood fibers) which can also present a highly varied composition, depending on the chemical composition of wood. The outstanding natural durability of wood is conferred by its significant content in extractives, which act as an effective barrier against biologic attack.

There are many factors affecting the chemical composition of wood, the habitat of the trees included. Consequently, the amount of individual structural components varies depending on the tree species, age, or part (roots, stem, bark, branches) as well. For example, hardwoods generate high amounts of ash in comparison with softwoods, just like bark and leaves when compared with other parts of trees. Analyzing the ash amounts, it can be assessed that high amounts of minerals corresponds to an intense dehydration, which is a worldwide situation under certain climate circumstances. The holocellulose represents the total fraction of polysaccharides in wood ( $\alpha$-cellulose and hemicelluloses), and its high content in wood species may increase correspondingly the yield of pulp for paper production.

Some correlations can be established between wood's chemical composition and its further exploitation according to particular circumstances of climate changes and pollution. The content of the main structural polymers from wood, cellulose and lignin, as well as other components, undergoes notable changes in response to air pollution (Waliszewska et al. 2019). The wood subjected to different harmful conditions, including pollutants, can be used as a valid bioindicator of decomposition processes of the constitutive polysaccharides, expressed by the changes in the ratios holocellulose/lignin and cellulose/lignin.

Annual climate changes directly affect the trees physiology by modifying the amount of constitutive polymers and their interrelation, and such details are revealed by dendrochronology, with the analysis of stable isotopes in wood (Leonelli et al. 2012; Trahan and Schubert 2016; Kwak et al. 2016). The wood's isotopic composition can be altered upon exposure to pollution events (e.g. emissions of nitrogen oxides, carbon dioxide, or sulphur dioxide are captured and assimilated by trees through leaves) or polluted environments (e.g. ozone resulting from chemical reactions in soil under heat and sunlight; heavy metals deposition in soil, on the bark and leaves from trees, both determining their accumulation in wood cell walls, further altering physiological response with visible effects on the wood isotopic composition), while climate conditions modulate trees growth and consequently natural isotopic composition.

The content of the stable carbon isotope $\delta^{13} \mathrm{C}$ is largely linked in cellulose to the photosynthesis rate and can supply relevant information on water uptake and related processes, so that wood exposed to climatic conditions with variable humidity is acting as a bioindicator. Thus, the carbon storage is significantly increased in various trees species living in water deficient areas (Saini 2017); therefore, they can be further used for the 
development of new afforestation strategies aiming at urban zones with enriched green infrastructure.

\section{References Cited}

Albrechtová, P., Mauer, O., Gebauer, R., Hurt, V., and Kacálek, D. (2016). “A comparative study of above- and below-ground parameters of healthy and declining young Norway spruce trees in a mountain area affected by air pollution," Scand. J. For. Res. 32(6), 481-487. DOI:10.1080/02827581.2016.1249023

Kocić, K., Spasić, T., Urošević, M. A., and Tomašević, M. (2014). "Trees as natural barriers against heavy metal pollution and their role in the protection of cultural heritage," J. Cult. Herit. 15(3), 227-233. DOI: 10.1016/j.culher.2013.05.001

Kwak, J.-H., Lim, S.-S., Lee, K.-S., Viet, H. D., Matsushima, M., Lee, K.-H., Jung, K., Kim, H.-Y., Lee, S.-M., Chang, S. X., and Choi, W.-J. (2016). "Temperature and air pollution affected tree ring $\delta^{13} \mathrm{C}$ and water-use efficiency of pine and oak trees under rising $\mathrm{CO}_{2}$ in a humid temperate forest," Chem. Geol. 420, 127-138.

DOI:10.1016/j.chemgeo.2015.11.015

Lemonick, S. (2018). "Looking for Finland's future in its forests," ACS Cent. Sci. 4, 424427. DOI: $10.1021 /$ acscentsci.8b00202

Leonelli, G., Battipaglia, G., Siegwolf, R. T. W., Saurer, M., Morra di Cella, U., Cherubini, P., and Pelfini, M. (2012). "Climatic isotope signals in tree rings masked by air pollution: A case study conducted along the Mont Blanc Tunnel access road (Western Alps, Italy)," Atmos. Environ. 61, 169-179. DOI:10.1016/j.atmosenv.2012.07.023

Saini, D. (2017). "Screening and evaluation of candidate trees for terrestrial carbon storage in regions with high air pollution and water stress," Carbon Manag. 8(5-6), 445-456. DOI:10.1080/17583004.2017.1404387

Schäfer, H., Bossel, H., Krieger, H., and Trost, N. (1988). "Modelling the responses of mature forest trees to air pollution," GeoJournal 17(2), 279-287.

Trahan, M. W., and Schubert, B. A. (2016). "Temperature-induced water stress in highlatitude forests in response to natural and anthropogenic warming, " Global Change Biol. 22(2), 782-791. DOI:10.1111/gcb.13121

Waliszewska, B., Mleczek, M., Zborowska, M., Golinski, P., Rutkowski, P., and Szentner, K. (2019). "Changes in the chemical composition and the structure of cellulose and lignin in elm wood exposed to various forms of arsenic," Cellulose 26, 6303-6315. DOI: 10.1007/s10570-019-02511-z 